This item was submitted to Loughborough's Research Repository by the author.

Items in Figshare are protected by copyright, with all rights reserved, unless otherwise indicated.

\title{
Results From England's 2016 report card on physical activity for children and youth
}

PLEASE CITE THE PUBLISHED VERSION

http://dx.doi.org/10.1123/jpah.2016-0298

\section{PUBLISHER}

(c) Human Kinetics, Inc.

\section{VERSION}

AM (Accepted Manuscript)

\section{PUBLISHER STATEMENT}

This work is made available according to the conditions of the Creative Commons Attribution-NonCommercialNoDerivatives 4.0 International (CC BY-NC-ND 4.0) licence. Full details of this licence are available at: https://creativecommons.org/licenses/by-nc-nd/4.0/

\section{LICENCE}

CC BY-NC-ND 4.0

\section{REPOSITORY RECORD}

Wilkie, Hannah, Martyn Standage, Lauren Sherar, Sean P. Cumming, Caley Parnell, Adrian Davis, Charlie E. Foster, and Russ Jago. 2019. "Results from England's 2016 Report Card on Physical Activity for Children and Youth". figshare. https://hdl.handle.net/2134/23947. 
Full title: Results from England's 2016 Report Card on Physical Activity for Children and Youth

Running head: England’s 2016 Report Card

Manuscript type: Brief Report

Key words: exercise, policy, sedentary behavior, adolescent guidelines and recommendations, public health

Abstract word count: 195

Manuscript word count: 4685

Date of Manuscript Submission: 30 ${ }^{\text {th }}$ May 2016 


\section{Abstract}

2 Background: Regular physical activity improves physical and mental health, yet children’s 3 physical activity levels were low in England's 2014 Report Card. Within this paper, we update 4 the 2014 Report Card to assess current information for the nine indicators of physical activity.

5 Methods: A search for nationally representative data on nine indicators of physical activity was

6 conducted and the data were assessed by an expert panel. The panel assigned grades (i.e. A, B,

7 C, D, F, or INC (incomplete)) to each indicator based on whether children across England were

8 achieving specific benchmarks. The 2016 Report Card was produced and disseminated.

9 Results: The following grades were awarded: Overall Physical Activity Levels: D-; Organized

10 Sport Participation: D; Active Play: INC; Active Transportation: C-; Sedentary Behaviours: INC;

11 Family and Peers: INC; School: B+; Community and the Built Environment: B; Government

12 Strategies and Investment: INC.

13 Conclusions: The grades have not improved since the 2014 Report Card and several gaps in the

14 literature are still present. While children’s physical activity levels remain low alongside

15 competing sedentary choices, further national plans and investment with local actions are

16 urgently needed to promote physical activity especially via active play, active transport, and

17 family support.

18

19 Key words: exercise, policy, sedentary behavior, adolescent, guidelines and recommendations, 20 public health 


\section{Introduction}

25 According to government recommendations, children in the United Kingdom (UK) aged 5-18

26 years should be engaging in moderate-to-vigorous intensity physical activity (MVPA) for at least

2760 minutes every day. ${ }^{1}$ However, children’s physical activity (PA) levels appear to be low. One recent estimate reported that only $9 \%$ of boys and $2 \%$ of girls achieved sufficient levels of objectively measured PA. ${ }^{2}$ Given the health risks ${ }^{3-5}$ and the economic costs associated with

30 physical inactivity, ${ }^{6}$ it is important to understand the prevalence of PA and sedentary behaviour 31 among children and youth across England, including the extent to which PA is supported by 32 government policy and the built environment. Active Healthy Kids England was established in 2014 with the aim of providing a 'state of the nation’ resource by creating England’s first Report Card on Physical Activity for Children and Youth. ${ }^{7}$ Several gaps in the literature were identified and PA levels were generally low despite there being evidence of sufficient provision for PA in England. ${ }^{7}$

37 The purpose of the present paper is to discuss the results of the 2016 Report Card on Physical Activity for Children and Youth. Specifically, we update the 2014 Report Card via the use of

39 newly available data, including published work from a variety of academic and non-academic sources (e.g., from government and non-government organisations).

\section{Methods} Active Healthy Kids England consists of an expert panel, including several academics from five

44 Universities across England, and a representative involved in research within a leading nongovernmental organisation (Youth Sport Trust; YST). The lead author identified key articles and 
47 author was also responsible for writing the Report Card and additional resources (e.g., website content). All members contributed to the grade assignment process by providing expertise in their relevant field. In addition, the second author was responsible for creating a media and dissemination strategy with assistance from the YST (fifth author). Nine indicators of PA were assessed: 1) Overall Physical Activity Levels, 2) Organized Sport Participation, 3) Active Play, 4) Active Transportation, 5) Sedentary Behaviours, 6) Family and Peers, 7) School, 8) Community and the Built Environment, 9) Government Strategies and Investment. Data used to inform the grades for these indicators were provided from several national surveys including the Health Behaviour in School Aged Children Study (HBSC), ${ }^{8}$ the Health Survey for England (HSE), ${ }^{9}$ the Millennium Cohort Study (MCS), ${ }^{10,11}$ the Taking Part Survey (TPS), ${ }^{12}$ the National Travel Survey (NTS), ${ }^{13}$ and the YST National PE and Sport Survey. ${ }^{14}$ Reports from the government and the Office for Standards in Education, Children's Services and Skills (Ofsted) were also referred to throughout, as were regional datasets and reports from other organisations when data were not available from national surveys.

The grade assignment meeting took place in April 2016 where members of the expert panel assessed the available evidence, and assigned grades to each indicator once agreement had been reached. The quality of the available data was considered by taking into account the sample size, age range of participants, year of data collection, the reach of the sample (i.e., whether data were collected regionally or across England), and the measures used to collect data. Other factors were considered in the grade assignment, including trends in PA behaviours and the presence of any disparities between groups of children (e.g., age, gender, and ethnic differences). When such differences occurred, $\mathrm{a}+$ or - grade was given to reflect this. The following grade boundaries were used: A: $81 \%-100 \%$, B: 61\%-80\%, C: 41\%-60\%, D: 21\%-40\%, F: 0-20\%. An incomplete 

71 suitable benchmark.

72

73

\section{4}

75

76

77

78

79

80

81

82

83

84

85

86

87

88

89

90

91

92

81

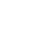

(INC) grade was assigned where insufficient data were available or due to the absence of a

\section{Results}

England's 2016 Report Card is the second iteration of a systematic assessment of PA among children and youth. The grades and benchmarks for each indicator are presented in Table 1, and the front cover is shown in Figure 1. No improvement in any indicator has been made since the 2014 Report Card. For several indicators (Overall Physical Activity Levels, Organized Sports Participation, Active Transportation, and Schools), the grade has declined, whereas for others (Active Play, Sedentary Behaviours, Family and Peers, Community and the Built Environment, Government Strategies and Investment), the grade remains the same.

\section{Discussion}

The expert panel decided to focus the 2016 theme and front cover on informal outdoor PA. The benefits of informal activity, such as active play and active transport, including time spent outdoors in relation to PA are well documented. ${ }^{15-17}$ Yet the proportion of children who walk to school has declined since $1995 / 97,{ }^{18}$ and less than $50 \%$ of children use active means to travel to non-school destinations. ${ }^{11,19}$ Furthermore, active play typically occurs outside, ${ }^{20}$ but it would appear that children spend less time outdoors now than their parents did as they have less 'freedom to roam'. ${ }^{21,22}$ Future research is therefore needed on informal outdoor PA, especially given that time spent indoors may largely consist of engaging in sedentary pursuits. ${ }^{23}$ 


\section{Overall Physical Activity Levels: D-}

A grade of D- was assigned to children's overall PA levels because boys and girls are consistently within the $\mathrm{D}$ and $\mathrm{F}$ grade boundaries respectively, according to self-reported data from a number of surveys. For example, according to the HBSC, $22 \%$ of boys and $15 \%$ of girls aged 11, 13 and 15 years are achieving 60 minutes of MVPA per day. ${ }^{8}$ Similar figures were reported in the HSE (21\% of boys and 16\% of girls aged 5-15 years), ${ }^{9}$ and the UK Household Longitudinal Study (35.8\% of boys and $21.8 \%$ of girls aged $10-15$ years). ${ }^{24}$ Even lower levels were reported among 15 year olds specifically in the What About Youth Survey (18\% of boys and 9\% of girls). ${ }^{25}$ The grade has therefore declined since the 2014 Report Card, in which a grade of C/D was awarded, ${ }^{7}$ though this may in part be due to a lack of available data on children younger than 11 years old. There is also a distinct lack of objective data available to grade this indicator, though existing guidelines were developed using self-reported estimates of PA which raises the question of whether current guidelines are suitable given that objective estimates of PA tend to show much lower PA levels. Despite this, these findings emphasise the need for regular monitoring of children's PA levels, using objective measures on a wide age range of children and youth, in order to track changes in PA behaviour over time. ${ }^{7}$

\section{Organized Sport Participation: D}

Although data from the Active People and Taking Part Surveys show that $>70 \%$ of children and youth were doing sport at least once a week, ${ }^{12,26}$ this may include sport inside of school and was therefore not used to inform the grade. On examination of the data for those involved in organized sport outside of school hours the figures are lower. For example, 34.3\% of 5-15 year olds reported doing organized sport outside of school; only $27.4 \%$ of $11-15$ s were members of an external sports club and only $19.2 \%$ played for a sports team. ${ }^{12}$ Yet again, a higher proportion of 
116 boys than girls are engaged in organized sport (35\% vs. 21\%). ${ }^{27}$ Aside from sport, 39\% of 8-11

117 year olds participate in organized leisure-time activities once or twice a week and 20\% do so

118 every day or almost every day. ${ }^{28}$ Given that the majority of data since the last Report Card now

119 resides within the $\mathrm{D}$ grade boundary, the grade was reduced from a C- to a D.

120 Active Play: INC

121 A lack of available data and appropriate definitional means for measuring this indicator was cited 122 in the 2014 Report Card and an INC grade was assigned. ${ }^{7}$ The same issues are still apparent and

123 consequently, an INC grade was awarded again. Despite this, younger children are likely

124 engaging in active play, particularly during school break times. ${ }^{29}$ Yet, participation in physically

125 active play declines with age as a function of biological maturity. ${ }^{30}$ For example, recent data

126 from the MCS show $80 \%$ of 5 year olds engage in active play with a parent at least once or twice

127 a week, whereas $54 \%$ of 11 year olds do so. ${ }^{10}$ Data are therefore also needed on the type and

128 frequency of unstructured PA performed by adolescents, particularly because it may help to

129 reduce health inequalities. ${ }^{16}$

130 Active Transportation: C-

131 Data from the NTS and MCS informed this grade, and similar to the 2014 Report Card, 47\%-

$13251 \%$ of children actively commute to or from school, though only $2 \%$ of these children go by

133 bicycle. $^{11,13}$ Approximately 55\% of primary schools offered Bikeability cycle training in 2012,,

134 though according to a recent evaluation of the scheme, there was no evidence of increased

135 cycling frequency levels among children. ${ }^{32}$ Additional measures may be needed, including

136 changes to the built environment (e.g., segregated cycle lanes and traffic free routes), if we are to

137 improve both bicycle safety and cycling levels across England. ${ }^{33,34}$ 
138 In terms of active transport to non-school destinations, general bike use is slightly better with

$13928 \%$ of 11 year olds reporting the use of their bike several times a week, ${ }^{11}$ and $47 \%$ of $2-16$ year

140 olds walk for 20 minutes or more, 3 or more times a week. ${ }^{19}$ However, boys are more likely to

141 travel on their own by bike (36\% vs. 23\%) and by foot (54\% vs. 44\%) than girls, according to the

$142 \mathrm{MCS}^{11}$ which likely reflects the higher level of independent mobility typically given to boys. ${ }^{35}$

143 Due to the lack of improvement on this indicator, the consistently low levels of bike use, and the

144 lower proportion of girls making journeys on their own by active means, the panel decided to

145 drop the C grade to a C-. However, it must be noted that some children may use other forms of

146 active travel not considered here (e.g. scooters, roller blades, skate boards etc.) and some

147 journeys may be made using both passive and active means. An internationally agreed definition

148 and metric of active travel is necessary to facilitate comparisons across countries.

149 Sedentary Behaviours: INC

150 An INC grade was assigned to this indicator for a second year, because there are currently no UK

151 guidelines which specify a threshold for sedentary time that can be used as a benchmark. ${ }^{7}$

152 Furthermore, there is a lack of available data on children's engagement in sedentary behaviours

153 with the exception of recreational screen time, which shows that $62 \%$ of young people reported

154 watching TV and screen-based media for $>2$ hours per day. ${ }^{8}$ However, past research has

155 focussed heavily on TV viewing alone but children and young people have access to a wide

156 range of screen-based entertainment, ${ }^{36}$ thus future research is needed on the effects that this may

157 have on children's health. Data on other non-screen based sedentary behaviours are also

158 required, particularly since children who engage in high screen time may be more sedentary in

159 general. ${ }^{37}$ In order for a grade to be assigned in future Report Cards, and to advance this area of

160 research, specific evidence-based guidelines for sedentary behaviours are needed in the UK. 


\section{Family and Peers: INC}

162 For a second time, an INC grade was awarded to this indicator due to a lack of nationally

163 representative data on family and peer support for PA in England. ${ }^{7}$ Data from the YST shows

164 that 53\% of parents are engaged in their child's extra-curricular PA and sport at school, though

165 only 8\% of these parents are reported to be 'completely engaged' (2015 YST; unpublished

166 custom analysis). However, it is unclear what is meant by 'engaged' in terms of the type of

167 support provided by parents, thus these data were not used to inform a grade. Only one

168 benchmark, which examined the proportion of children doing sport/PA as a family could be

169 assigned a grade. This benchmark was given a D grade because $41 \%$ of young people do PA

170 with their family at least once a week. ${ }^{8}$

\section{School: B+}

172 Five benchmarks were assessed, including a new benchmark on the proportion of schools who 173 have a specialist teacher delivering curriculum Physical Education (PE). This new benchmark 174 contributed to the decline in the overall school grade from an A- to a B+ overall.

175 Data from the PE and Sport Survey ${ }^{38}$ were used to inform the A- grade for school PE in the 2014 176 Report Card. ${ }^{7}$ This survey was discontinued from 2010, and PE is no longer monitored annually 177 across all schools in England. ${ }^{39}$ However, data have been collected recently by the YST, which 178 was used to inform the grades for the majority of the school benchmarks. According to this 179 survey, 77\% of schools offer at least 2 hours of PE per week at Key Stage 1 (ages 5-7); this rises 180 to $83 \%$ and $86 \%$ at Key Stages 2 (ages 7-11) and 3 (ages 11-14) respectively, but provision drops 181 to 58\% at Key Stage 4 (ages 14-16) (2015 YST; unpublished custom analysis). In addition, > $18297 \%$ of schools report offering extra-curricular PA and sport, and $85 \%$ of secondary and $97 \%$ of 183 primary schools report encouraging PA as part of the school day. ${ }^{14}$ As such, a B+ was assigned 
184 for school PE, and an A grade was awarded to both the availability of additional opportunities 185 and the promotion of daily PA benchmarks. As 57\% of schools reported having a specialist PE 186 teacher, with more secondary schools (86\%) providing this than primary schools (44\%) (2015

187 YST; unpublished custom analysis), a B- was awarded to the provision of a PE specialist 188 benchmark.

189 As for the provision of PA facilities at school, data from a report on spending the PE and Sport 190 Premium (£150 million ring-fenced funding provided to all primary schools in England ${ }^{*}$ ) was 191 used. $^{41}$ This report shows that $46 \%$ of primary schools have access to outside courts, $64 \%-78 \%$ 192 have access to a multi-purpose school hall, swimming pool and playing field, and 100\% have 193 access to a playground. ${ }^{41}$ It is a statutory requirement for schools to provide outdoor space for 194 PA, though this does not apply to pupil referral units (an establishment for those who are unable 195 to attend mainstream school), ${ }^{42}$ and according to a consultation by Sport England, approximately 1963000 primary schools do not have adequate outdoor space for PA and sport. ${ }^{43}$ Furthermore, the 197 benchmark specifies that facilities should be in 'good condition', but the only indication of the 198 quality of such facilities is that $47 \%$ of schools thought the quality and $45 \%$ thought the range of 199 their facilities had improved since the introduction of the PE and Sport Premium. ${ }^{41}$ Further, 30\% 200 of young people say they would play more sport if their school had better facilities. ${ }^{27}$ As such, it 201 is possible that some school facilities may need improvement and little is known about provision 202 across secondary schools. Taking this into account, the grade for this benchmark was reduced 203 from an A to a $\mathrm{B}+$.

\section{Community and the Built Environment: B}

\footnotetext{
*This funding will be doubled from April 2018 as part of the new sugar tax. ${ }^{40}$
} 
205 The grade for this indicator has not changed and remains at a B. ${ }^{7}$ Four benchmarks were used to

206 measure this indicator, pertaining to access to and use of outdoor parks and spaces, satisfaction

207 with such spaces and perceptions of safety within the local neighbourhood.

208 According to data from the MCS, 93.4\% of 11 year olds have a playground available to them 209 where they live, and $61.2 \%$ of 5 year olds are taken to a playground weekly. ${ }^{10}$ Other data show 210 that $70 \%$ of children visit the natural environment at least once a week. ${ }^{44}$ Consequently, A and B 211 grades were awarded for access to and use of outdoor parks and spaces respectively. In terms of 212 satisfaction with these spaces, a C grade was assigned because $59 \%$ of park managers, and 50\% 213 of park visitors, feel that their parks are in good condition. ${ }^{45}$

214 It is promising that $72 \%$ of young people agreed that it is safe for children to play outdoors 215 during the day where they live according to the HBSC, ${ }^{8}$ and a higher proportion of parents 216 (86.4\%), ${ }^{46}$ and 11 year olds (89\%) ${ }^{11}$ report that their home area is safe, according to the MCS. A 217 B+ was awarded to this benchmark to place emphasis on the HBSC data, given that it is more 218 relevant to PA in particular, and the + was included to reflect the higher percentage reported in 219 the MCS. An area for consideration in future Report Cards is the perception of traffic safety and 220 the proportion of children who are allowed to leave the house to play outdoors/actively travel to 221 places unsupervised. This will provide a better indication of neighbourhood safety and whether 222 the spaces near to home are adequately suited to PA behaviours.

223 Government Strategies and Investment: INC

224 Akin to the 2014 Report Card, grading this indicator was difficult due to a lack of independent 225 evaluation of different strategies and policies that are currently in place. ${ }^{7}$ Thus, we do not know 226 how successful such policies are in terms of promoting PA participation among children and 227 youth. However, due to the lack of improvement across all grades in the 2016 Report Card, it 
228 would seem unlikely that current policies and strategies are having a significant impact on a

229 large scale.

230 Strengths and Limitations

231 The 2016 Report Card has a number of strengths. First, it is the only review of its kind available 232 in England which includes an overall assessment of multiple PA behaviours and varying levels 233 of influence among children and youth. Second, it is a useful resource which can be used by a 234 number of people including public health practitioners, teachers, parents and others that have an 235 influence on children's PA levels. It can also be used to influence future policy directions, serve 236 as a tool for developing future research ideas, and guide research funding priorities. ${ }^{7}$ Further, a 237 number of experts in the field were involved in the grade assignment.

238 Despite these strengths, some limitations should be highlighted. For example, there is a lack of 239 available data to measure some indicators which was also the case for England's 2014 Report

240 Card. $^{7}$ Although the best available evidence was used to inform the grades, there is a need for 241 continuous monitoring of children’s PA participation using objective measures on a wide age 242 range of participants (e.g., from 2-18 years). In addition, there are still no UK specific guidelines 243 for sedentary behaviour. Such guidelines are needed if we are to grade this indicator in future, 244 and a systematic surveillance tool that captures nationally representative data akin with all 245 benchmarks is needed.

\section{Conclusion}

248 In conclusion, the grades reflect that PA levels are low among children and youth across

249 England. There has been no improvement since the last edition of the Report Card, with many 250 grades having declined, and a lack of available data to measure some indicators. Despite this, 
251 there is still sufficient provision of facilities and PA programmes for children and youth,

252 reflected in the $\mathrm{B}+$ and $\mathrm{B}$ grades awarded to the school and community indicators. Thus, further

253 work is needed to understand how to promote the use of such facilities and programmes.

254

255 Acknowledgements

256 The authors thank Professor Stuart Biddle (Victoria University) for his contribution to the 2016

257 Report Card, pertaining to the Sedentary Behaviour indicator.

258 


\section{References}

1. Department of Health. Start active, stay active: a report on physical activity for health from the four home countries' Chief Medical Officers. London, UK: Department of Health; 2011. www.gov.uk/government/uploads/system/uploads/attachment_data/file/216370/dh_1282 10.pdf. Accessed May 26, 2016.

2. Cooper AR, Goodman A, Page AS, et al. Objectively measured physical activity and sedentary time in youth: the International children's accelerometry database (ICAD). Int J Behav Nutr Phys Act. 2015;12:113.

3. Andersen LB, Harro M, Sardinha LB, et al. Physical activity and clustered cardiovascular risk in children: a cross-sectional study (The European Youth Heart Study). Lancet. 2006;368:299-304.

4. World Health Organization. Global Status Report on Noncommunicable Diseases 2010. Geneva: World Health Organization; 2011.

5. Kushi LH, Doyle C, McCullough M, et al. American Cancer Society guidelines on nutrition and physical activity for cancer prevention: reducing the risk of cancer with healthy food choices and physical activity. CA Cancer J Clin. 2012;62:30-67.

6. Evans K. The inactivity time bomb. The economic cost of physical inactivity in young people: A StreetGames/Cebr report. Centre for Economics and Business Research; 2014. http://www.streetgames.org/sites/default/files/The-Inactivity-TimeBomb-StreetGamesCebr-report-April-2014.pdf. Accessed May 26, 2016. 
281 7. Standage M, Wilkie HJ, Jago R, Foster C, Goad MA, Cumming SP. Results from

282 England's 2014 report card on physical activity for children and youth. $J$ Phys Act Health. 283 2014;11(suppl 1):S45-S50.

284 8. Brooks F, Magnusson J, Klemera E, Chester K, Spencer N, Smeeton N. HBSC England 285 National Report 2014. Hatfield, UK: University of Hertfordshire; 2015.

286 287

288

289

290

291

292

293

294

295

296

297

298

299

300

301

302

9. Scholes S, Mindell J. Physical activity in children. In: Craig R, Mindell J, eds. Health Survey for England 2012. Volume 1: Health, Social Care and Lifestyles. Leeds, UK: The Health and Social Care Information Centre; 2013:1-41.

10. Goisis A, Sacker A, Kelly Y. Why are poorer children at higher risk of obesity and overweight? A UK cohort study [published online December 10 2015]. Eur J Public Health. 2015. doi: 10.1093/eurpub/ckv219.

11. Platt L. Millennium Cohort Study: Initial findings from the age 11 survey. Centre for Longitudinal Studies; 2014. Available at www.cls.ioe.ac.uk. Accessed Sep 27, 2016.

12. Department for Culture Media and Sport. Taking part 2014/15 annual child report. London, UK: Department for Culture Media and Sport; 2015. https://www.gov.uk/government/uploads/system/uploads/attachment_data/file/447730/Ta king_Part_2014_15_Child_Report_Repaired_.pdf. Accessed May 26, 2016.

13. Department for Transport. Table NTS0615 Usual mode of travel to school by age group: England, 2002 to 2014. Department for Transport; 2016. Available at https://www.gov.uk/government/statistical-data-sets/nts06-age-gender-and-modalbreakdown. Accessed May 26, 2016.

14. Youth Sport Trust. YST National PE, school sport and physical activity survey report January 2015. Youth Sport Trust; 2015. 
https://www.youthsporttrust.org/sites/yst/files/resources/pdf/national_pe_school_sport_a nd_physical_activity_survey_report.pdf. Accessed May 26, 2016.

15. Sallis JF, Prochaska JJ, Taylor WC. A review of correlates of physical activity of children and adolescents. Med Sci Sports Exerc. 2000;32:963-975.

16. Payne S, Townsend N, Foster C. The physical activity profile of active children in England. Int J Behav Nutr Phys Act. 2013;10:136.

17. Smith L, Sahlqvist S, Ogilvie D, Jones A, Griffin SJ, van Sluijs E. Is active travel to nonschool destinations associated with physical activity in primary school children? Prev

18. Department for Transport. National Travel Survey: England 2014. Department for Transport; 2015. https://www.gov.uk/government/uploads/system/uploads/attachment_data/file/457752/nts

19. Department for Transport. Table NTS0312 Walks of 20 minutes or more by age: 2014-01.pdf. Accessed May 26, 2016.

20. Brockman R, Fox KR, Jago R. What is the meaning and nature of active play for today's children in the UK? Int J Behav Nutr Phys Act. 2011;8:15.

323 21. Brussoni M, Gibbons R, Gray C, et al. What is the relationship between risky outdoor 324 play and health in children? A systematic review. Int J Environ Res Public Health. 2015;12:6423-6454. 
326 22. Playday. Playday 2013 opinion poll summary. 2013. Available at

327 http://playday.gn.apc.org/2013-opinion-poll/.

328 23. Gray C, Gibbons R, Larouche R, et al. What is the relationship between outdoor time and physical activity, sedentary behaviour, and physical fitness in children? A systematic review. Int J Environ Res Public Health. 2015;12:6455-6474.

331 24. McAloney K, Graham H, Law C, Platt L, Wardle H, Hall J. Fruit and vegetable consumption and sports participation among UK youth. Int J Public Health. 2014;59:117-121.

25. Ipsos MORI. Health and wellbeing of 15 year olds in England: Findings from the What Accessed May 26, 2016.

26. Sport England. Once a week overall participation (factsheet APS9 Q4). Available at 339 https://www.sportengland.org/media/10745/1x30_overall_factsheet_aps10q2.pdf.

341 27. The class of 2035. Promoting a brighter and more active future for the youth of tomorrow. Future Foundation; 2015. https://issuu.com/youthsporttrust/docs/the_class_of_2035. Accessed May 26, 2016.

344 28. The Children's Society. The good childhood report 2015. London: The Children's Society; 2015. 
348 29. Ridgers ND, Carter LM, Stratton G, McKenzie TL. Examining children's physical activity and play behaviors during school playtime over time. Health Educ Res. 2011;26:586-595.

30. Byers JA. The biology of human play. Child Dev. 1998;69:599-600.

31. Goodman A, van Sluijs EMF, Ogilvie D. Cycle training for children: which schools offer it and who takes part? J Transp Health. 2015;2:512-521.

32. Goodman A, van Sluijs EMF, Ogilvie D. Impact of offering cycle training in schools upon cycling behaviour: a natural experimental study. Int J Behav Nutr Phys Act. 2016;13:34.

33. Aldred R. Adults' attitudes towards child cycling: a study of the impact of infrastructure. Eur J Transp Infrastruct Res. 2015;15:92-115.

34. Pucher J, Buehler R. Making cycling irresistible: lessons from The Netherlands, Denmark and Germany. Transp Rev. 2008;28:495-528.

35. Stone MR, Faulkner GE, Mitra R, Buliung RN. The freedom to explore: examining the influence of independent mobility on weekday, weekend and after-school physical activity behaviour in children living in urban and inner-suburban neighbourhoods of varying socioeconomic status. Int J Behav Nutr Phys Act. 2014;11:5.

36. Ofcom. Children and parents: Media use and attitudes report. 2015. http://stakeholders.ofcom.org.uk/binaries/research/media-literacy/children-parents-nov15/childrens_parents_nov2015.pdf. Accessed May 26, 2016.

37. Sandercock GRH, Ogunleye A, Voss C. Screen time and physical activity in youth: thief of time or lifestyle choice? J Phys Act Health. 2012;9:977-984. 
370 38. Quick S, Simon A, Thornton A. PE and sport survey 2009/10. TNS-BMRB; 2010.

371

372

373

374

375

376

377

378

379

380

381

382

383

384

385

386

387

388

389

390

391

392 https://www.gov.uk/government/uploads/system/uploads/attachment_data/file/181556/D FE-RR032.pdf. Accessed May 26, 2016.

39. Department for Education. Evidence on physical education and sport in schools. Department for Education; 2013. https://www.gov.uk/government/uploads/system/uploads/attachment_data/file/226505/Ev idence_on_physical_education_and_sport_in_schools.pdf. Accessed May 26, 2016.

40. Budget 2016: Some of the things we've announced [news release]. HM Treasury and The RT Hon George Osborne MP; March 16, 2016.

https://www.gov.uk/government/news/budget-2016-some-of-the-things-weve-announced. Accessed May 26, 2016.

41. Callanan M, Fry A, Plunkett M, Chanfreau J, Tanner E. The PE and sport premium: an investigation in primary schools. NatCen Social Research; 2015.

https://www.gov.uk/government/uploads/system/uploads/attachment_data/file/489477/D FE-RR489_PE_and_sport_premium_an_investigation_in_primary_schools__final_report.pdf. Accessed May 26, 2016.

42. The School Premises (England) Regulations 2012, No. 1943 Regulation 10. 2012. http://www.legislation.gov.uk/uksi/2012/1943/regulation/10/made. Accessed May 26, 2016.

43. Sport England. Primary spaces website. http://funding.sportengland.org/funding/ourdifferent-funds/primary-spaces. Accessed May 26, 2016.

44. Natural England. Monitor of engagement with the natural environment: a pilot to develop an indicator of visits to the natural environment by children. Natural England; 2016. 

https://www.gov.uk/government/uploads/system/uploads/attachment_data/file/498944/m ene-childrens-report-years-1-2.pdf. Accessed May 26, 2016.

395 45. Heritage Lottery Fund. State of UK public parks 2014: Renaissance to risk? 2014. Available at https://www.hlf.org.uk/state-uk-public-parks. Accessed May 26, 2016.

397 46. Pouliou T, Sera F, Griffiths L, et al. Environmental influences on children's physical activity [published online October 30 2014]. J Epidemiol Community Health. 2015;69:77-85. doi: 10.1136/jech-2014-204287. 
Tables

401

Table 1. Grades According to Physical Activity Indicators assessed in England’s 2016 Report Card on Physical Activity for Children and Youth

Indicator

\section{Benchmark(s)}

Grades

Overall Physical $\%$ of children/youth achieving $\geq 60$ minutes of MVPA per day

Activity Levels

Organized Sport

$\%$ of children/youth participating in organized sport/PA programmes out of school time

Participation

Active Play

\% of children/youth engaging in daily unstructured/unorganized active play

INC

Active Transportation

$\%$ of children/youth who use active transport to get to and from places (school, park etc.)

paying membership fees, driving etc.)

$\%$ of parents who do sport/PA with their children

$\%$ of children/youth who have friends that support them to be physically active 
School

\% of schools allocating at least 120 minutes of curriculum PE per week

$\mathrm{B}+$

$\%$ of schools with specialist PE teachers

\% of schools that offer additional PA opportunities (excluding PE)

$\%$ of schools that promote PA as part of the school day

$\%$ of pupils who have access to PA facilities at school (e.g., sports hall, outdoor playground)

that are in good condition

Community and the

$\%$ of children/youth with access to outdoor parks and spaces

$\%$ of children/youth who use outdoor parks and spaces

$\%$ of children/youth who are satisfied with their local outdoor parks and spaces

$\%$ of children/parents who perceive their neighbourhood to be safe

Government Strategies

Evidence of allocated funds and PA promotion strategies/initiatives for all children and youth and Investment

404

Note. The grade boundaries for each indicator are: $A$ is $81 \%$ to $100 \%$; $B$ is $61 \%$ to $80 \%$; $C$ is $41 \%$ to $60 \%, D$ is $21 \%$ to $40 \%$; $F$ is $0 \%$

to $20 \%$; INC is Incomplete data.

MVPA, moderate-to-vigorous intensity physical activity; PA, physical activity; PE, physical education. 
411 Figure 1: Front Cover of England's 2016 Physical Activity Report Card
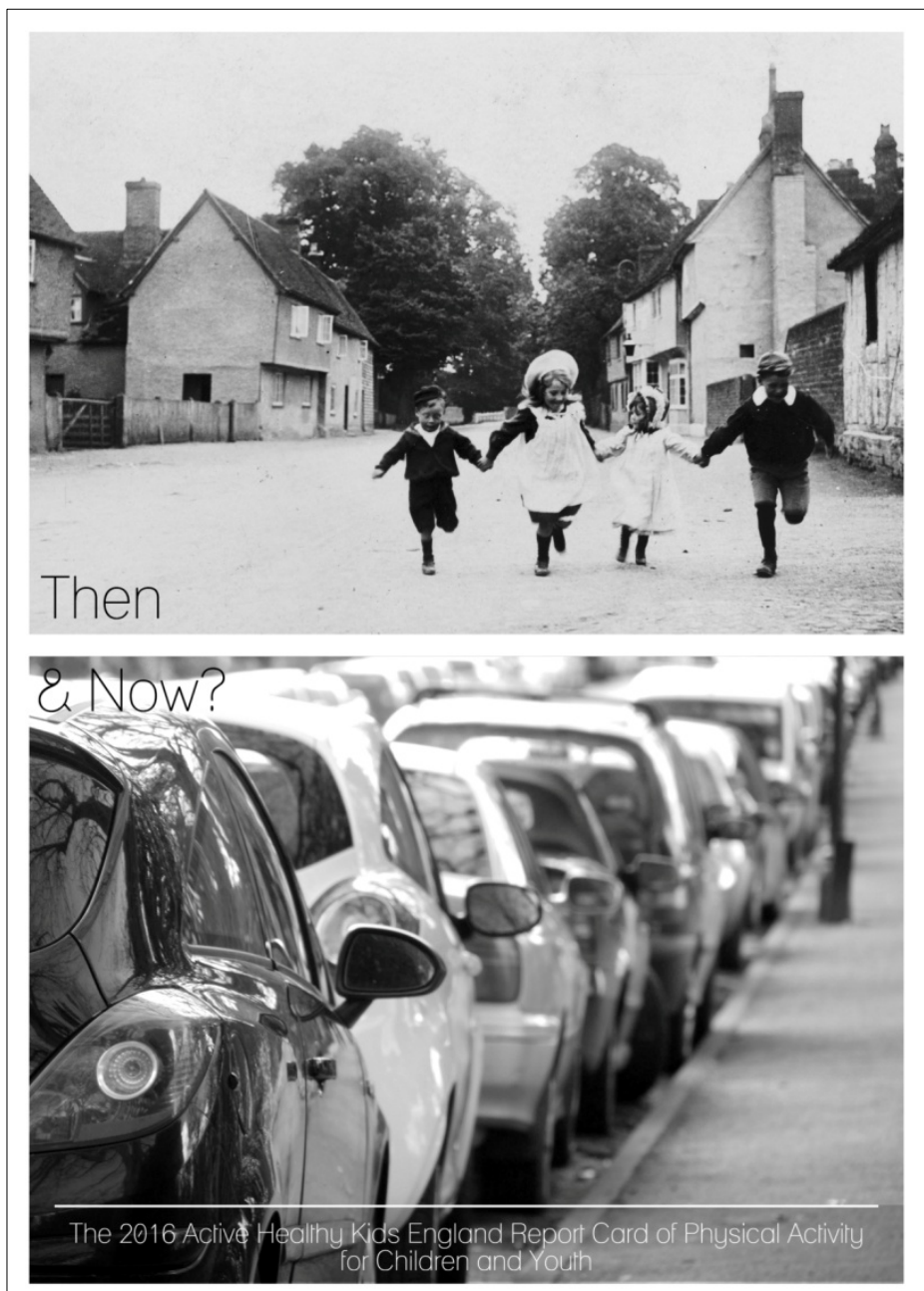